\title{
ASSOCIATION BETWEEN AN MHC CLASS II ALLELE AND GLEARANCE OF HEPATITIS B VIRUS IN THE GAMBIA
}

\author{
Mark R. Thursz, M.R.C.P., Dominic Kwiatkowski, M.R.C.P., Catherine E.M. Allsopp, Ph.D., \\ Brian M. Greenwood, F.R.G.P., Howard G. Thomas, Ph.D., and Adrian V.S. Hill, D.M.
}

\begin{abstract}
Background. The course of hepatitis B virus (HBV) infection does not appear to be determined by variations in viral virulence and may be influenced by the host immune response. We studied the distribution of human leukocyte antigens in children and adult men in the Gambia who spontaneously recovered from HBV infection as compared with the distribution of these antigens in subjects with persistent infection.

Methods. In a two-stage, case-control study, we analyzed the frequency of MHC class I antigens and class II haplotypes in subjects with either transient or persistent HBV infection. MHC class I typing was performed by microlymphocytotoxicity assays. MHC class II typing was performed with analysis of restriction-fragment-length polymorphisms (RFLPs), supplemented by other techniques.

Results. In the first stage (the study of children up to the age of 10 years), the RFLP pattern 25-1, which includes the class II allele HLA-DRB1*1302, was found in 58 of 218 subjects with transient HBV infection (26.6 per-
\end{abstract}

$\mathrm{I}^{\mathrm{N}}$ NFECTION with the hepatitis B virus (HBV) may result in a number of conditions ranging from asymptomatic persistent carriage to fulminant hepatitis with liver failure. Most infected people have acute hepatitis during which the virus is eliminated. About 80 percent of adults in West Africa have been infected with HBV, and in about 15 percent of these persons the virus is not cleared. ${ }^{1}$ Persistent HBV infection predisposes patients to chronic liver disease and hepatocellular carcinoma ${ }^{2}$; HBV-related hepatocellular carcinoma is the leading cause of death among men of working age in the Gambia. ${ }^{3,4}$

The outcome of HBV infection does not appear to be determined by variations in virulence among viral strains. Instead, the course of the disease may be influenced by the host immune response. Although a small proportion of people with persistent infection have specific types of immunodeficiency, such as human immunodeficiency virus (HIV) infection ${ }^{5}$ or agammaglobulinemia, ${ }^{6}$ the majority are not immunocompromised. In West Africa, children under the age of 10 years acquire HBV infection asymptomatically from older siblings or playmates, although the mechanism of transmission is unclear. $^{7,8}$ Mother-to-child transmission such as that seen in the Far East is rare. An immature immune sys-

From the Hepatology Unit, Academic Department of Medicine, St. Mary's Hospital Medical School, Imperial College, London (M.R.T., H.C.T.); the Institute of Molecular Medicine, University of Oxford, John Radcliffe Hospital, Oxford, United Kingdom (D.K., C.E.M.A., A.V.S.H.); and the Medical Research Council Laboratories, Fajara, the Gambia (B.M.G., A.V.S.H.). Address reprint requests to Dr. Thursz at the Department of Medicine, St. Mary's Hospital Medical School, London W2 1NY, United Kingdom.

Supported by Boehringer-Mannheim, the Wellcome Trust, and the Medical Research Council, United Kingdom, and by a grant from Applied Immune Sciences, Inc. (to Dr. Thursz). Dr. Hill is a Wellcome Trust Senior Clinical Fellow. Dr. Kwiatkowski is a Senior Clinical Fellow of the Medical Research Council. cent) and 30 of 185 subjects with persistent infection (16.2 percent) (relative risk of carrying the $25-1$ pattern in the persistently infected group as compared with the transiently infected group, 0.53; 95 percent confidence interval, 0.32 to $0.90 ; \mathrm{P}=0.012$ ). In the second stage (the study of adults), HLA-DRB1*1302 was found in 50 of 195 subjects with transient HBV infection (25.6 percent) and in 3 of 40 subjects with persistent infection ( 7.5 percent) (relative risk, $0.24 ; 95$ percent confidence interval, 0.04 to $0.80 ; \mathrm{P}=0.012$ ). The RFLP pattern 13-2, which includes the class II allele DRB1*1301, was less frequent in children with persistent infection than in those with transient infection, an association that was neither confirmed nor excluded by the data on adults. Possible associations with HLA class I antigens found in children were not supported by the data on adults.

Conclusions. The MHC class II allele DRB $1 * 1302$ was associated with protection against persistent HBV infection among both children and adults in the Gambia. (N Engl J Med 1995;332:1065-9.)

tem, as seen in newborns, and the tolerance-producing effects of the transplacental transfer of HBV e antigen are unlikely to affect the outcome of infection.

Variations in immune response are often associated with polymorphism of the major histocompatibility complex (MHC). The role of the MHC phenotype in the outcome of HBV infection has been examined, but no firm conclusion has been reached. ${ }^{9-13}$ Many studies have been only large enough (with 33 to 79 subjects positive for hepatitis B surface antigen) to detect very strong associations between the MHC phenotype and the disease state. Most of these studies have used serologic methods of MHC class II typing. Such methods diminish sensitivity, because they assign a large number of alleles to the same serologic specificity.

We compared the distribution of HLA antigens in children and adults in the Gambia who spontaneously recovered from $\mathrm{HBV}$ infection with the distribution of antigens in those with persistent infection.

\section{MethodS}

\section{Study Subjects}

The study subjects were all West Africans living in the western, coastal region of the Gambia in the area surrounding the capital, Banjul. Two different groups were recruited between 1988 and 1990 for two stages of the study. In the first stage, children up to 10 years of age were recruited at the Royal Victoria Hospital, Banjul, and the Medical Research Council (MRG) Hospital, Fajara, where they had been seen for a variety of conditions unrelated to HBV. In the second stage, adult men were recruited from among healthy blood donors. Both groups had previously been studied as part of a case-control study of susceptibility to malaria. ${ }^{14}$ Permission for the study was granted by the Joint Ethics Committee, and the study was approved by the Scientific Coordinating Committee. Consent for phlebotomy was obtained from each child's parent or guardian.

In both stages, the subjects were grouped according to the results of serologic tests for HBV. People who had never been exposed to 
$\mathrm{HBV}$ were negative for antibodies against the HBV core antigen (hereafter referred to as HBV core antibody). People who had spontaneously recovered from $\mathrm{HBV}$ infection were positive for IgG $\mathrm{HBV}$ core antibody and negative for HBV surface antigen. People with persistent HBV infection were positive for both HBV core antibody and hepatitis B surface antigen. People with recent $\mathrm{HBV}$ infection who may not have had sufficient opportunity to eliminate hepatitis B surface antigen (i.e., those who were positive for that antigen and for $\operatorname{IgM}$ HBV core antibody) were excluded from the analysis. One hundred seven people who had been vaccinated against $\mathrm{HBV}$ were classified as unexposed and were not included in the analysis of HLA frequencies. Five people with HIV antibodies were excluded from the analysis.

\section{Serologic Testing}

Plasma samples were obtained from all subjects and stored at $-20^{\circ} \mathrm{C}$. Their serologic status with regard to HBV core antibody, IgM HBV core antibody, and hepatitis B surface antigen and the concentrations of antibody to hepatitis B surface antigen were determined by enzyme-linked immunosorbent assay (ELISA) according to the manufacturer's instructions (Boehringer-Mannheim, Munich, Germany). HIV-antibody status was determined by ELISA (Wellcozyme, Wellcome, Beckenham, United Kingdom), with positive tests confirmed by the Western blot assay.

\section{MHC Typing}

Class I serotyping was performed on lymphocytes, which were available from about half the subjects in each group. Serologic MHC class I types were determined by standard microlymphocytotoxicity assays of fresh or cryopreserved cells, using 180 well-characterized types of antiserum. ${ }^{14}$ MHC class II typing was performed by analysis of restriction-fragment-length polymorphisms (RFLPs) as described elsewhere, with the restriction enzymes TaqI and Bam HI. ${ }^{14,15}$ In this assay, band patterns determined by Southern blot analysis correspond to MHC class II haplotypes and are expressed as two numbers separated by a hyphen (e.g., 13-2, 25-1). This analysis was supplemented, when necessary, by amplification by the polymerase chain reaction and blotting with sequence-specific oligonucleotides. ${ }^{14,15}$ All subjects were assigned an MHC class II type.

\section{Statistical Analysis}

The frequencies of MHC class I phenotypes and of RFLP-defined class II haplotypes were compared between people who had recovered from HBV infection and those with persistent infection with regard to $23 \mathrm{MHC}$ class I antigens and 10 class II haplotypes by the chi-square test. When multiple comparisons are made concurrently, apparently significant associations may arise by chance. To avoid such errors, we first made multiple comparisons in the first group (children), and then tested them in the second group (adults) with a restricted hypothesis generated during the first stage of study ${ }^{16}$ Relative risks, calculated from the crude odds ratios and given with 95 percent confidence intervals, reflect the likelihood of carrying a specific MHC type in the persistently infected group as compared with the transiently infected group. The ethnic composition of the Gambia is mixed, containing Mandinka (42 percent), Jola (14 percent), Wolof (14 percent), and Fula (12 percent), as well as several less common groups. ${ }^{15}$ Therefore, Mantel-Haenszel tests were performed to assess a possible confounding effect of ethnic origin. Among the adults, concentrations of antibody to hepatitis B surface antigen were compared between subjects with HLA-DRB1*1302 and those without that allele, by the unpaired t-test.

\section{Results}

Of the 1344 children recruited, 891 were unexposed and 453 (33.7 percent) were positive for HBV core antibody. Of these, 185 (40.8 percent) were positive for hepatitis B surface antigen and negative for IgM HBV core antibody (i.e., they had persistent infection), and 218 (48.1 percent) were positive for IgG HBV core antibody, negative for IgM HBV core antibody, and negative for hepatitis B surface antigen (i.e., they had transient infection). The remaining 50 children (11.0 percent) were excluded from the study because they were positive for both hepatitis B surface antigen and IgM HBV core antibody (i.e., they had recent infection). The increase in the carriage of HBV core antibody and hepatitis B surface antigen with age is shown in Figure 1. Of the 260 adults, 25 were unexposed and 235 (90.4 percent) were positive for HBV core antibody. Of these, 40 (17.0 percent) had persistent infection, and 195 (82.9 percent) had transient infection. The frequencies of MHC class I antigens and class II haplotypes in the children are shown in Tables 1 and 2 , respectively, and those in the adults are shown in Tables 1 and 3 .

Possible associations between the MHC class I antigens HLA-B50 (relative risk, undefinable; 95 percent confidence interval, 1.2 to $\infty ; \mathrm{P}=0.015)$ and $H L A-C w 1$ (relative risk, 9.82; 95 percent confidence interval, 1.2 to $448 ; \mathrm{P}=0.02$ ) and persistent carriage of hepatitis $\mathrm{B}$ surface antigen were suggested by the data from the study of children (Table 1). These associations, however, were not supported by the data from the study of adults (Table 1). Although none of the class I phenotypes studied were associated with clearance of HBV, the power of this study to detect class I associations was lower than the power to detect class II associations, because only about half the subjects underwent MHC class I typing, and class I antigens are more diverse than class II antigens in this population.

MHC class II haplotypes were initially determined with the restriction enzyme TaqI. ${ }^{15}$ The RFLP pattern 25-1, which corresponds to the class II haplotypes $D R B 1 * 1302-D R B 3 * 0301-D Q A 1 * 0102-D Q B 1 * 0501$ (DRw13/DQw5) and DRB1*1302-DRB3*0301$D Q A 1 * 0102-D Q B 1 * 0604$ (DRw13/DQw6), was found in 58 of the 218 children with transient HBV infection (26.6 percent) and in 30 of the 185 children with persistent infection (16.2 percent) (relative risk, $0.53 ; 95$ percent confidence interval, 0.32 to $0.90 ; \mathrm{P}=0.012$ ) (Table 2). This pattern was associated with a protective effect against persistent carriage of HBV. The RFLP pattern 13-2, which corresponds to the class II haplotype $D R B 1 * 1301-D R B 3 * 0101-D Q A 1 * 0103-D Q B 1 * 0603$, was also reduced in frequency in persistently infected children (relative risk, 0.35; 95 percent confidence interval, 0.1 to $1.0 ; \mathrm{P}=0.037$ ). No other haplotype studied showed a significant alteration in frequency.

We then analyzed these two possible associations in the adult group. HLA-DRB1*1302 was found in 50 of 195 adults with transient HBV infection (25.6 percent) and 3 of 40 adults with persistent infection (7.5 percent) (relative risk, 0.24; 95 percent confidence interval, 0.04 to $0.80 ; \mathrm{P}=0.012$ ) (Table 3 ). After stratification according to ethnic group, the Mantel-Haenszel weighted relative risk was 0.23 (95 percent confidence interval, 0.05 to $0.83 ; \mathrm{P}=0.022$ ), and the possibility of a significant confounding effect of ethnic origin was thereby excluded. The possible association with $H L A$ $D R B 1 * 1301$ was neither confirmed nor excluded by the data on adults. $H L A-D R B 1 * 1301$ was present in 1 of 40 


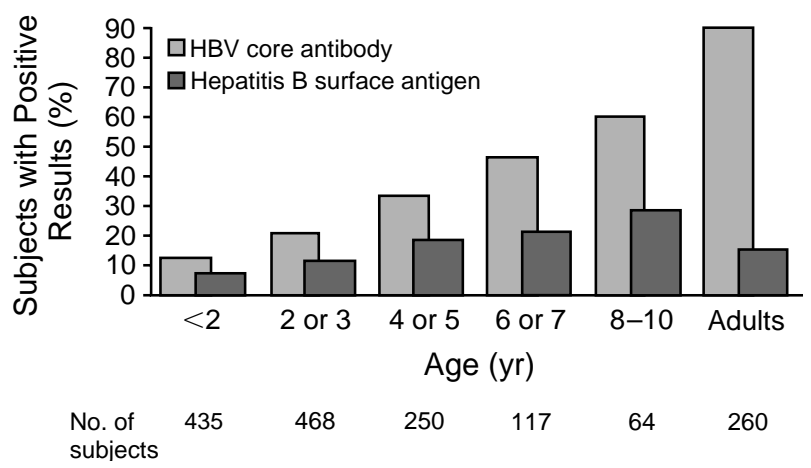

Figure 1. Increase in the Prevalence of Antibody against the HBV Core Antigen and Changes in the Carriage of Hepatitis B Surface Antigen with Age in the Gambia.

Mother-to-child transmission is not a major route of transmission in this population. Carriage of hepatitis B surface antigen in adults was lower than that in 10-year-old children, suggesting that the elimination of HBV may often be completed during adolescence. The number of subjects in each age group is shown below the graph.

adults with persistent infection and in 7 of 195 adults with transient infection (odds ratio, 0.69; 95 percent confidence interval, 0.02 to $5.62 ; \mathrm{P}=1.0$ ).

Children and adults with the RFLP pattern 25-1 were further subdivided according to whether they had the $D Q w 5$ or the $D Q w 6$ allele. Relative risks and 95 percent confidence intervals were calculated for the two haplotypes (Table 4), and the elimination of HBV was found to be associated with both. This indicates that protection from persistent carriage of HBV was primarily associated with HLA-DR rather than with the HLA-DQ molecules encoded by the RFLP 25-1 pattern, a localization that is important in analyzing the molecular basis of this finding.

A possible confounding effect of variation in the closely linked $T N F \alpha$ gene promoter was analyzed. Among these subjects, $H L A-D R B 1 * 1302$ and a TNF $\alpha$ promoter variant are in linkage disequilibrium. ${ }^{17}$ Stratified analyses indicated that the effect of HLA-DR was independent of the $T N F \alpha$ gene polymorphism (data not shown). In 25 adults with $D R B 1 * 1302$ (mean age, 28.6 years), the mean $( \pm \mathrm{SD})$ concentration of antibody to hepatitis B surface antigen was $15.5 \pm 41.5$ IU per liter. In 25 adults without $D R B 1 * 1302$ (mean age, 32.2 years), the mean concentration of antibody to hepatitis $\mathrm{B}$ surface antigen was $22.3 \pm 48.5(\mathrm{P}=0.598)$.

\section{Discussion}

We found an association between the RFLP-defined MHC class II haplotype 25-1 and clearance of HBV infection among groups of children and adults in the Gambia. The 25-1 pattern represents two MHC class II haplotypes, $D R B 1 * 1302-D R B 3 * 0301-D Q A 1 *$ $0102-D Q B 1 * 0501$ and $D R B 1 * 1302-D R B 3 * 0301-$ $D Q A 1 * 0102-D Q B 1 * 0604$. Further analysis showed that both $D R B 1 * 1302$ haplotypes were associated with the clearance of $\mathrm{HBV}$; it is therefore probable that one or both of the shared HLA-DR alleles are responsible for this association. $H L A-D R B 1 * 1302$ is found only on the 25-1 RFLP pattern, whereas HLA-DRB $3 * 0301$ is also found on other RFLP-defined haplotypes in the Gambia. ${ }^{15}$ Furthermore, the product of DRB $1 * 1302$ is expressed at a higher level than the product of $D R B 3$ and may thus be of greater functional importance, particularly because $\mathrm{T}$ cells restricted by products of the $D R B 1$ locus are identified more frequently than are $D R B 3$-restricted $\mathrm{T}$ cells with regard to most antigens.

The RFLP pattern 13-2, which corresponds to the class II haplotype $D R B 1 * 1301-D R B 3 * 0101-$ $D Q A 1 * 0103-D Q B 1 * 0603$, may also be associated with resistance to persistent HBV infection, as suggested by the data on persistently infected children. Interestingly, the DRB1 allele of this haplotype, $D R B 1 * 1301$, differs from $H L A-D R B 1 * 1302$ by the substitution of a single amino acid, a change of glycine $(* 1302)$ to valine (*1301) at position 86 of the DR $\beta$ chain. Combining the data on adults and children with RFLP pattern 13-2 gives a relative risk for persistent infection of 0.46 (95 percent confidence interval, 0.15 to $1.20 ; \mathrm{P}=0.09$ ). Our data are therefore consistent with the hypothesis that both $D R B 1 * 1302$ and $D R B 1 * 1301$ protect against persistent $\mathrm{HBV}$ infection.

It is possible that RFLP pattern 25-1 is a marker for a linked non-HLA-DR gene variant that confers protection against persistent $\mathrm{HBV}$ infection. We believe

Table 1. Frequencies of MHC Class I Antigens in Children and Adults with Persistent or Transient HBV Infection.

\begin{tabular}{|c|c|c|c|c|}
\hline \multirow[t]{3}{*}{$\begin{array}{c}\text { MHC } \\
\text { ANTIGEN* }\end{array}$} & \multicolumn{2}{|c|}{ ChILDREN } & \multicolumn{2}{|c|}{ Adults } \\
\hline & $\begin{array}{l}\text { PERSISTENT } \\
\text { INFECTION } \\
(\mathrm{N}=64)\end{array}$ & $\begin{array}{c}\text { TRANSIENT } \\
\text { INFECTION } \\
(\mathrm{N}=81)\end{array}$ & $\begin{array}{l}\text { PERSISTENT } \\
\text { INFECTION } \\
(\mathrm{N}=14)\end{array}$ & $\begin{array}{l}\text { TRANSIENT } \\
\text { INFECTION } \\
(\mathrm{N}=69)\end{array}$ \\
\hline & \multicolumn{4}{|c|}{ no. of subjects (\% of group) } \\
\hline A1 & $9(14.1)$ & $11(13.6)$ & $1(7.1)$ & $13(18.8)$ \\
\hline A2 & $15(23.4)$ & $17(21.0)$ & $5(35.7)$ & $19(27.5)$ \\
\hline A3 & $4(6.3)$ & $7(8.6)$ & 0 & $5(7.3)$ \\
\hline A23 & 14 (21.9) & $21(25.9)$ & 4 (28.6) & $15(21.7)$ \\
\hline A26 & $12(18.8)$ & $13(16.0)$ & $3(21.4)$ & $8(11.6)$ \\
\hline A28 & $11(17.2)$ & $19(23.5)$ & $3(21.4)$ & $8(11.6)$ \\
\hline A30 & $17(26.6)$ & $19(23.5)$ & 4 (28.6) & $15(21.7)$ \\
\hline A33 & $16(25.0)$ & $20(24.7)$ & $6(42.9)$ & $18(26.1)$ \\
\hline B7 & $9(14.1)$ & $11(13.6)$ & $4(28.6)$ & $9(13.0)$ \\
\hline B8 & $20(31.3)$ & $16(19.8)$ & $2(14.3)$ & $11(15.9)$ \\
\hline B17 & $12(18.8)$ & $14(17.3)$ & $2(14.3)$ & $14(20.3)$ \\
\hline B35 & $20(31.3)$ & $23(28.4)$ & $5(35.7)$ & $20(29.0)$ \\
\hline B50 & $5(7.8)$ & $0 \dagger$ & 0 & $2(2.9)$ \\
\hline B53 & $9(14.1)$ & $15(18.5)$ & $5(35.7)$ & $17(24.6)$ \\
\hline B70 & $9(14.1)$ & $9(11.1)$ & 0 & $11(15.9)$ \\
\hline $\mathrm{Cw} 1$ & $7(10.9)$ & $1(1.2) \ddagger$ & 0 & $5(7.3)$ \\
\hline $\mathrm{Cw} 2$ & $9(14.1)$ & $4(4.9)$ & 0 & 17 (24.6) \\
\hline Cw3 & $16(25.0)$ & $29(35.8)$ & $3(21.4)$ & $24(34.8)$ \\
\hline Cw4 & $13(20.3)$ & $26(32.1)$ & $6(42.9)$ & $20(29.0)$ \\
\hline Cw6 & $10(15.6)$ & $8(9.9)$ & $3(21.4)$ & $11(15.9)$ \\
\hline $\mathrm{Cw} 7$ & $12(18.8)$ & $19(23.5)$ & $4(28.6)$ & $9(13.0)$ \\
\hline Cw8 & $4(6.3)$ & $9(11.1)$ & $1(7.1)$ & $2(2.9)$ \\
\hline
\end{tabular}

*As determined by a standard microlymphocytotoxicity assay. Only antigens with frequencies of 5 percent or more were analyzed.

$\dagger \mathrm{P}=0.010$.

\$Relative risk, 9.82 (95 percent confidence interval, 1.19 to 448.2 ); $\mathrm{P}=0.02$. 
Table 2. Frequencies of RFLP-Defined Class II Haplotypes in Children with Persistent or Transient HBV Infection.

\begin{tabular}{|c|c|c|c|c|}
\hline RFLP PATTERN & DRB1 ALLELE & DQ TYPE & $\begin{array}{l}\text { PERSISTENT } \\
\text { INFECTION } \\
(\mathrm{N}=185)\end{array}$ & $\begin{array}{l}\text { TRAnsiEnt } \\
\text { InFECTION } \\
(\mathrm{N}=218)\end{array}$ \\
\hline & & & \multicolumn{2}{|c|}{ no. (\%) of subjects } \\
\hline $1-1$ & 01 & w5 & $14(7.6)$ & $17(7.8)$ \\
\hline $4-4$ & 04 & w8 & $11(5.9)$ & $24(11.0)$ \\
\hline $6-3$ & 0301 & w2 & $9(4.9)$ & $17(3.2)$ \\
\hline $7-9$ & 09 & w2 & $26(14.1)$ & $32(14.7)$ \\
\hline $8-5$ & 08 & w7 & $16(8.6)$ & $13(6.0)$ \\
\hline $10-1$ & 10 & w5 & 33 (17.8) & $33(15.1)$ \\
\hline $13-2$ & 1301 & w6 & $5(2.7)$ & $16(7.3)^{*}$ \\
\hline $18-4$ & 0302 & w4 & $7(3.8)$ & $10(4.6)$ \\
\hline $21-5$ & 1304 & w7 & $86(46.5)$ & $109(50.0)$ \\
\hline $25-1$ & 1302 & w5/w6 & $30(16.2)$ & $58(26.6) \dagger$ \\
\hline
\end{tabular}

*Relative risk, 0.35 (95 percent confidence interval, 0.1 to 1.0 ); $\mathrm{P}=0.037$.

$\dagger$ Relative risk, 0.53 (95 percent confidence interval, 0.31 to 0.90 ); $\mathrm{P}=0.012$.

Table 3. Frequencies of RFLP-Defined Class II Haplotypes in Adults with Persistent or Transient HBV Infection.

\begin{tabular}{|c|c|c|c|c|}
\hline RFLP PATTERN & DRB1 Allele & DQ TYPE & $\begin{array}{c}\text { Persistent } \\
\text { INFECTION } \\
(\mathrm{N}=40)\end{array}$ & $\begin{array}{l}\text { TRANSIENT } \\
\text { INFECTION } \\
(\mathrm{N}=195)\end{array}$ \\
\hline & & & \multicolumn{2}{|c|}{ no. (\%) of subjects } \\
\hline $1-1$ & 01 & w5 & $2(5)$ & $11(5.6)$ \\
\hline $4-4$ & 04 & w8 & $2(5)$ & $19(9.7)$ \\
\hline $6-3$ & 0301 & w2 & $1(2.5)$ & $7(4.6)$ \\
\hline $7-9$ & 09 & w2 & 7 (17.5) & $24(12.3)$ \\
\hline $8-5$ & 08 & w7 & $4(10)$ & $9(4.6)$ \\
\hline $10-1$ & 10 & w5 & $6(15)$ & $28(14.4)$ \\
\hline $13-2$ & 1301 & w6 & $1(2.5)$ & $7(3.6)^{*}$ \\
\hline $18-4$ & 0302 & w4 & $4(10)$ & $6(3.1)$ \\
\hline $21-5$ & 1304 & w7 & $21(52.5)$ & $80(41)$ \\
\hline $25-1$ & 1302 & w5/w6 & $3(7.5)$ & $50(25.6) \dagger$ \\
\hline
\end{tabular}

*Relative risk, 0.69 (95 percent confidence interval, 0.02 to 5.62); $\mathrm{P}=1.0$.

$\dagger$ Relative risk, 0.24 (95 percent confidence interval, 0.04 to 0.80 ); $\mathrm{P}=0.012$.

Table 4. Differential Analysis of the Relative Risk Associated with Individual $D R B 1 * 1302$ Haplotypes.*

\begin{tabular}{ccccc}
\hline \hline Population & Persistent & Transient & Relative Risk (95\% & \\
and DQ Type & Infection & Infection & Confidence Interval) & P Value
\end{tabular}

$$
\text { no. of subjects }
$$

$\begin{array}{ccccc}\text { Children } & & & & \\ \text { DQ5 } & 22 & 34 & 0.73(0.39-1.35) & 0.28 \\ \text { DQ6 } & 12 & 26 & 0.51(0.24-1.11) & 0.06 \\ \text { Adults } & & & & \\ \text { DQ5 } & 3 & 34 & 0.38(0.07-1.33) & 0.12 \\ \text { DQ6 } & 0 & 18 & 0(0-1.0) & 0.05\end{array}$

*The RFLP-defined haplotype 25-1 represents two MHC class II haplotypes $D R B 1 * 1302-D R B 3 * 0301-D Q A 1 * 0102-D Q B 1 * 0501$ (DRw13/DQw5) and DRB1*1302$D R B 3 * 0301-D Q A 1 * 0102-D Q B 1 * 0604 / 05$ (DRw13/DQw6). The 25-1 pattern was subdivided by oligonucleotide probing and RFLP analysis into the DQ5 and DQ6 types, and the relative risk was calculated for both. Because both haplotypes were associated with elimination of $\mathrm{HBV}$, we inferred that the $D R B I * 1302$ allele was more likely than the DQ alleles to be responsible for the association.

that this is unlikely. On one side of HLA-DR lies the $T N F \alpha$ promoter polymorphism, which is in strong linkage disequilibrium with $D R B 1 * 1302$ in this population but is not associated with protection from persistent HBV infection. On the other side of HLA-DR, the HLA-DQ variants that were analyzed also showed no association. Therefore, on RFLP pattern 25-1, HLA$D R B 1 * 1302$ seems most likely to be associated with protection against persistent $\mathrm{HBV}$ infection.

$H L A-D R B 1 * 1302$ is also associated with a reduced risk of severe malaria in Gambian children. This finding may help to explain the high frequency of the $D R B 1 * 1302-D R B 3 * 0301-D Q A 1 * 0102-D Q B 1 * 0501$ and $D R B 1 * 1302-D R B 3 * 0301-D Q A 1 * 0102-D Q B 1 * 0604$ haplotypes in this population. ${ }^{11}$ Malaria and HBV are both important causes of premature death in West Africa. Severe malaria has a high death rate in children under the age of five years. Deaths from HBV infection usually occur in adults. It is therefore possible that there is a selection advantage for the DRB1*1302 allele in the Gambia associated with both HBV and malaria.

Some children in West Africa carry hepatitis B surface antigen for several years before $\mathrm{HBV}$ is eliminated completely, and they may therefore have been misclassified as long-term carriers. This phenomenon may account for the lower relative risk of carrying the 25-1 haplotype in adult men with persistent HBV carriage as compared with children.

DRw6 - the serologic supertype of $D R B 1 * 1302$ and $D R B 1 * 1301$ — was identified in two previous studies as potentially protective against persistent $\mathrm{HBV}$ infection. Van Hattum et al. found DRw6 nearly twice as often in North European patients in whom HBV had cleared than in those who had not eliminated the virus. ${ }^{9}$ In a study of factors influencing the response of chronic HBV infection to interferon therapy, we found that DRw6 was associated with a favorable response. ${ }^{18}$ HLA-DRB1*1302 has been found in 10 to 26 percent of Africans and African Americans, 4 to 11 percent of whites, and 0 to 25 percent of Asians in large population surveys. ${ }^{19}$ The association we have identified may be relevant to other groups of people.

The activity of HBV-specific CD4+ T-helper cells is markedly reduced in patients with persistent infection as compared with patients who have acute, self-limiting infection. ${ }^{20}$ The responses of $\mathrm{T}$-helper cells increase during acute exacerbations of chronic HBV infection, particularly at the time of seroconversion from hepatitis $\mathrm{B}$ e antigen to antibody to hepatitis B e antigen. ${ }^{21}$ Through its role in antigen presentation, the class II molecule is critical to the development of T-helper-cell responses. The variable ability of class II molecules to present antigens may appear as variability in the response of T-helper cells. In patients with persistent HBV infection, failure to develop antibodies to hepatitis $\mathrm{B}$ e antigen and surface antigen, and to develop sufficient numbers of active HBV-specific cytotoxic T lymphocytes, may be related at least in part to the lack of T-helper-cell response mediated by class II molecules with relatively poor antigen-presenting ability. The finding of equivalent levels of antibodies to the hepatitis B surface antigen in people with and without $D R B 1 * 1302$ suggests that the mechanism of the MHC association is not mediated through the humoral response to this antigen.

A protective effect against cervical carcinoma related to the human papillomavirus has been reported that 
is associated with $D R B 1 * 1302$ and $D R B 1 * 1301 .{ }^{22} \mathrm{HBV}$, Plasmodium falciparum, and the human papillomavirus are complex microorganisms with many potential T-cell epitopes that have different MHC restriction elements. The MHC associations in these diseases suggest that only a small number of immune responses may be of particular importance for protection.

Recent advances in the study of peptides bound to MHC class I and II molecules and the identification of sequence motifs in bound peptides ${ }^{23,24}$ have facilitated the analysis of the molecular basis of associations between MHC types and disease. Using this approach, termed "reverse immunogenetics," we have identified a possible basis for the association of an MHC class I allele, $H L A-B 53$, with resistance to malaria in the Gambia. ${ }^{25}$ Analysis of the association of $H L A-D R B 1 * 1302$ with the clearance of HBV will be facilitated by the relatively small size of the HBV genome and the availability of its complete sequence. Recently, through the analysis of individual peptides eluted from both $H L A$ $D R B 1 * 1302$ and $H L A-D R B 1 * 1301$, we have identified related peptide-binding motifs for these alleles (unpublished data), allowing us to predict possible epitopes for these class II molecules.

Our findings implicate variation in the genes governing the immune response of the host as one factor that can explain the variable outcome of hepatitis B infection and offer an approach to elucidating the molecular mechanisms of viral clearance. Further analysis of this association may help identify strategies for the prevention and management of chronic HBV infection.

We are indebted to Hilton Whittle for reviewing the data and making valuable comments on the manuscript, to Estee Torok for assistance with the serologic assays, and to N. Anstey, P. Twumasi, D. Brewster, A. Hughes, L. Bayo, and L. Manneh for participating in the collection of samples.

\section{REFERENCES}

1. Ryder RW, Whittle HC, Wojiecowsky T, et al. Screening for hepatitis B virus markers is not justified in West African transfusion centres. Lancet 1984;2: 449-52.

2. Beasley RP, Hwang LY, Lin CC, Chien CS. Hepatocellular carcinoma and hepatitis B virus: a prospective study of 22707 men in Taiwan. Lancet 1981; 2:1129-33.

3. Ryder RW, Whittle HC, Sanneh AB, Ajdukiewicz AB, Tulloch S, Yvonnet B. Persistent hepatitis B virus infection and hepatoma in The Gambia, west Africa: a case-control study of 140 adults and their 603 family contacts. Am J Epidemiol 1992;136:1122-31.
4. Kiire CF. Hepatitis B infection in sub-Saharan Africa: the African Regional Study Group. Vaccine 1990;8:Suppl:S107-S112.

5. Krogsgaard K, Lindhardt BO, Nielsen JO, et al. The influence of HTLV-III infection on the natural history of hepatitis B virus infection in male homosexual HBsAg carriers. Hepatology 1987;7:37-41.

6. Hermaszewski RA, Webster AD. Primary hypogammaglobulinaemia: a survey of clinical manifestations and complications. Q J Med 1993;86:3142.

7. Marinier E, Barrois V, Larouze B, et al. Lack of perinatal transmission of hepatitis B virus infection in Senegal, West Africa. J Pediatr 1985;106:8439.

8. Botha JF, Ritchie MJ, Dusheiko GM, Mouton HW, Kew MC. Hepatitis B virus carrier state in black children in Ovamboland: role of perinatal and horizontal infection. Lancet 1984;1:1210-2.

9. van Hattum J, Schreuder GM, Schalm SW. HLA antigens in patients with various courses after hepatitis B virus infection. Hepatology 1987;7:114.

10. Forzani B, Actis GC, Verme G, et al. HLA-DR antigens in HBsAg-positive chronic active liver disease with and without associated delta infection. Hepatology 1984;4:1107-10

11. Lepage V, Degos F, Carella G, De Lima M, Giraud MC, Degos L. HLA-Cw7 and HBsAg negative chronic active hepatitis. Tissue Antigens 1981;18:1057.

12. Kaslow RA, Shaw S. The role of histocompatibility antigens (HLA) in infection. Epidemiol Rev 1981;3:90-114.

13. Almarri A, Batchelor JR. HLA and hepatitis B infection. Lancet 1994;344: $128-9$.

14. Hill AVS, Allsopp CE, Kwiatkowski D, et al. Common west African HLA antigens are associated with protection from severe malaria. Nature 1991; 352:595-600.

15. Hill AVS, Allsopp CE, Kwiatkowski D, et al. Extensive genetic diversity in the HLA class II region of Africans, with a focally predominant allele, DRB1*1304. Proc Natl Acad Sci U S A 1992;89:2277-81.

16. Hill AVS. HLA and infection. J R Coll Physicians Lond 1992;26:11-6.

17. McGuire W, Hill AVS, Allsopp CEM, Greenwood BM, Kwiatkowski D. Variation in the TNF-alpha promoter region associated with susceptibility to cerebral malaria. Nature 1994;371:508-10.

18. Scully L, Brown D, Lloyd C, Shein R, Thomas HC. Immunological studies before and during interferon therapy in chronic HBV infection: identification of factors predicting response. Hepatology 1990;12:1111-7.

19. Tsuji K, Aizawa M, Sasazuki T, eds. HLA 1991: proceedings of the eleventh annual international histocompatibility workshop and conference held in Yokohama, Japan, 6-13 November, 1991. Oxford, England: Oxford University Press, 1992.

20. Ferrari C, Penna A, Bertoletti A, et al. Cellular immune response to hepatitis $\mathrm{B}$ virus-encoded antigens in acute and chronic hepatitis B virus infection. J Immunol 1990;145:3442-9.

21. Tsai SL, Chen PJ, Lai MY, et al. Acute exacerbations of chronic type B hepatitis are accompanied by increased $\mathrm{T}$ cell responses to hepatitis $\mathrm{B}$ core and e antigens: implications for hepatitis B e antigen seroconversion. J Clin Invest 1992;89:87-96.

22. Apple RJ, Erlich HA, Klitz W, Manos MM, Becker TM, Wheeler CM. HLA DR-DQ associations with cervical carcinoma show papillomavirus-type specificity. Nat Genet 1994;6:157-62.

23. Falk K, Rotzschke O, Stevanovic S, Jung G, Rammensee HG. Allele-specific motifs revealed by sequencing of self-peptides eluted from MHC molecules. Nature 1991;351:290-6.

24. Chicz RM, Urban RG, Gorga JC, Vignali DA, Lane WS, Strominger JL. Specificity and promiscuity among naturally processed peptides bound to HLA-DR alleles. J Exp Med 1993;178:27-47.

25. Hill AVS, Elvin J, Willis AC, et al. Molecular analysis of the association of HLA-B53 and resistance to severe malaria. Nature 1992;360:434-9. 